\title{
MEINUNG
}

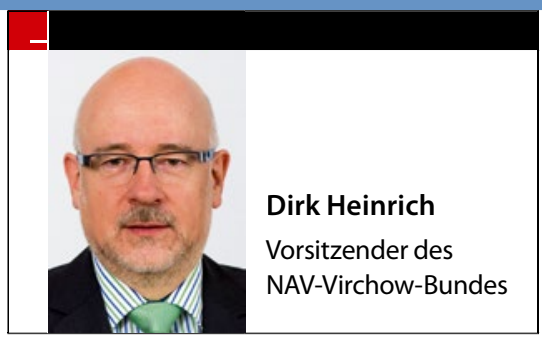

Anti-Korruptionsgesetz

\section{Wir bekommen ein unnötiges Sonderstrafrecht für Ärzte}

\begin{abstract}
Das Bundeskabinett hat schärfere Regeln gegen Korruption im Gesundheitswesen verabschiedet. Der Bundestag wird die neuen Straftatbestände wohl bald beschließen. Dr. Dirk Heinrich vom NAV-Virchow-Bund kritisiert, dass so Versorgungsmodelle behindert und Ärzte eingeschüchtert würden.
\end{abstract}

— Wer meint, wir Ärzte können tun und lassen, was wir wollen, irrt gewaltig. Die Palette der juristischen Werkzeuge gegen ärztliches Fehlverhalten ist breit gefächert: Es wird bereits strafrechtlich durch die Betrugs-, Körperverletzungsund Tötungsdelikte, zivilrechtlich durch die Arzthaftung, berufsrechtlich durch die Berufsgerichtsbarkeit, vertragsarztrechtlich durch Disziplinar- und Zulassungsentziehungsverfahren und approbationsrechtlich durch den Widerruf der Approbation geahndet. Mit dem „AntiKorruptionsgesetz" kommt nun ein weiteres Gesetz hinzu.

Die Neuregelung einer Bestechlichkeit für Heilberufe in den $\$ \$ 299$ a und $299 b$ StGB ist nichts anderes als ein Sonderstraftatbestand für Ärzte. Das bestehende Vertrauen in die Heilberufe wird massiv beschädigt. Erwünschte Kooperationen geraten schnell unter Korruptionsverdacht. Das von der Ärzteschaft gleichermaßen getragene Ziel, das Vertrauen der Patienten in die Integrität heilberuflicher Entscheidungen zu schützen und den Wettbewerb im Gesundheitswesen zu stützen, wird durch fehlende Praxistauglichkeit verfehlt.

Denn für den einzelnen Arzt bleibt ein erhebliches, nicht kalkulierbares Strafbarkeits- und Kriminalisierungsrisiko. Schuld ist die Weite und Unschärfe des im Gesetz formulierten Tatbestandes. In der Praxis stellt diese Profillosigkeit die Ärzte vor große Probleme: So ist kaum abgrenzbar, wann Zahlungen im Zusammenhang wirtschaftlicher Vereinbarun- gen oder Kooperationen als eine unlautere Beeinflussung des Wettbewerbs zu sehen sind. Mit der erfreulichen Vielzahl an Kooperationsarten im Gesundheitswesen geht nun eine ebenso große Unsicherheit ihrer Rechtmäßigkeit einher. Es steht zu befürchten, dass sich innovative

\section{I) Innovative Kooperation wird für Ärzte plötzlich riskant. «}

Versorgungsmodelle unter dem Damoklesschwert des Korruptionsstrafrechts zukünftig kaum mehr entwickeln können. Das Antikorruptionsgesetz könnte zur Innovationsbremse werden.

$\mathrm{Zu}$ kritisieren ist auch, dass das neue Gesetz auf das Berufsrecht zurückgreift. Dieses ist von Ärztekammer zu Ärztekammer unterschiedlich geregelt. In der Praxis könnte damit etwas strafbar sein, was im benachbarten Kam-

merbezirk keinen interessiert. Gerechtigkeit sieht anders aus!

Doch damit nicht genug. Bauchschmerzen bereitet auch das im Gesetz implementierte Antragsrecht von Krankenkassen und Versicherungsunternehmen. Dieses einseitig gewährte Sonderrecht birgt ein hohes Konfliktpotenzial und verzerrt den Wettbewerb zugunsten von Kassen und Versicherungen. So könnten sich zukünftig Kostenträger zur „Lösung“ wirtschaftlicher Konfliktfragen strafrechtlicher Mittel bedienen und Strafanträge gegen Leistungserbringer stellen - und sei es nur, um aus Sicht des Strafantragstellers begehrenswerte, diesem aber ansonsten verborgene Informationen aus Ermittlungsakten zutage zu fördern.

Angemerkt sei, dass es sich bei den aufgezählten Schwachstellen des Gesetzes um die fundierte Kritik des von der Allianz deutscher Ärzteverbände in Auftrag gegebenen Rechtsgutachtens der renommierten Strafrechtler Prof. Bernd Müssig und Dr. Daniel Neuhöfer, LL.M. handelt. Mit Blick auf die langfristigen Folgen muss außerdem festgehalten werden, dass dieses Gesetz nicht dazu beitragen wird, dem ärztlichen Nachwuchs die Niederlassung attraktiver zu machen - was angesichts der Probleme bei der Nachbesetzung von Praxissitzen jedoch von größter Dringlichkeit wäre.

Dr. med. Dirk Heinrich -

Bundesvorsitzender des NAV-Virchow-Bundes 